\title{
Paving the Road to Algal Biofuels with the Development of a Genetic Infrastructure
}

\author{
Julian N. Rosenberg, Michael J. Betenbaugh and George A. Oyler \\ Johns Hopkins University \\ United States
}

\section{Introduction}

It is anticipated that the global demand for energy will double within the next forty years (Hoffert et al., 1998). This leaves a relatively short period of time for a momentous shift in the fundamental sources of global energy. Nonetheless, satisfying our energy requirements with alternative sources can be achieved while allowing for continued technological progress, economic growth, and political stability over this period. The need for clean, sustainable energy sources is even more urgent when considered in light of the environmental consequences related to the liberation of carbon dioxide from fossil fuels.

For instance, increased production of electricity will undoubtedly necessitate a rapid expansion of nuclear, wind, solar, and hydro- power generation. Even if these sources of energy are aggressively developed, few alternatives appear to be available for the continued expansion of coal-based electricity extending to mid-century; thus, there is a pressing need for mechanisms of carbon dioxide $\left(\mathrm{CO}_{2}\right)$ abatement. Energy derived from biomass presents a means of both capturing $\mathrm{CO}_{2}$ and reducing the need for a fossil fuel-based infrastructure. As such, bioenergy has the advantage of being carbon neutral and will prove to be an important asset in our repertoire of renewable energy solutions.

In addition to producing energy from sustainable sources that maintain carbon neutrality, the obligation to use energy efficiently has never been more important - not only in our daily lives, but also in the mechanisms through which we will generate energy at large scales in the future. In biological systems, the utilization of energy is accomplished by a cascade of biochemical reactions mediated by tightly regulated metabolic networks, which are substantially more efficient than the internal combustion engine. One of the most important and impressive molecular mechanisms for harvesting energy is the photosynthetic process. While photovoltaic technology has improved considerably in recent decades, the plants and algae that have been refined over billions of years of evolution represent a fully developed living framework for solar energy collection.

\subsection{A focus on biofuels}

In the most general of terms, biofuels are biologically derived forms of chemical energy, such as hydrocarbons, that are compatible with the existing infrastructure. In a sense, petroleum is a biofuel because it is the oil-enriched remains of ancient biomass that has been unearthed. In a modern context, however, by actively converting photosynthetic biomass 
into liquid biofuel, solar energy can be readily stored and utilized to replace the use of petroleum as a transportation fuel. This is not a new concept; in fact, Rudolph Diesel envisioned his piston-driven engine to run on peanut oil so that farmers could grow their own fuel (Nitschke and Wilson, 1965). Currently, biofuels are gaining attention as a valuable piece of the renewable energy puzzle because they fit so seamlessly into the carbon cycle.

According to recent data, liquid transportation fuel use in the United States is between 130 and 140 billion gallons each year. This usage is anticipated to continue increasing to approximately 150 to 160 billion gallons per year, peaking around 2015 (U.S. Energy Information Administration, 2009). Fuel consumption appears likely to remain stable or decrease slowly as we approach the mid-century. Even in the United States, where a more rapid transition to hybrid or fuel-efficient vehicles is predicted, there will be a continued high demand for liquid transportation fuels.

In contrast to the high energy density of liquid fuels, hydrogen-based transportation seems to be a far-reaching goal and may never fully make sense for transportation. With current practices, hydrogen production is an energy intensive process and still requires a large investment in distribution infrastructure. Alternatively, plug-in electric vehicles have cost and environmental limitations related to batteries and would require a significant amount of time to replace the currently fleet of cars. For these reasons, an intensified focus on liquid biofuels is warranted. Moreover, liquid transportation fuels are currently the major use of petroleum throughout the world. In certain cases, the reliance on liquid fuels we have developed cannot easily be substituted (e.g. aviation, trucking, and construction industries). Furthermore, emerging economies will likely opt for the lowest cost vehicle solutions (i.e. internal combustion engines) and will still have a petroleum requirement.

\subsubsection{Ethanol: A first-generation biofuel}

Ethanol, by nature, has a lower energy density than other liquid fuels and is not entirely compatible with the current distribution infrastructure because it is hygroscopic and can contribute to rust formation. In the United States, ethanol produced in the Midwest also requires costly transportation to sites of consumption, primarily the East and West Coasts. In other parts of the world, particularly Brazil, where ethanol production may be more economically produced from sugar cane, there are still limitations including the high energy input for distillation from the dilute solutions produced biologically.

Biofuels made from food crops may impose stresses on the existing world economy. The most serious of these are the possible effect on food prices due to subsidized farming, substantial input of fossil fuels for production, degradation of agricultural land resources, and potential alterations in ecosystems from expanded land use. Even emissions of non- $\mathrm{CO}_{2}$ greenhouse gases may increase with first-generation biofuel production. The use of nitrogen fertilizer on biofuel crops also has the potential to increase the release of nitrous oxide, a greenhouse gas more potent than carbon dioxide, as well as the consumption of natural gas for fertilizer production. While first-generation ethanol has initiated the biofuel revolution, advanced biofuels are clearly needed.

\subsubsection{The next generation of biofuels}

With the limitations of ethanol as a biofuel and the need to expand beyond food crop-based biofuel production, there is a pressing need for second- and third-generation biofuels. Since 
there appears to be little consensus on the meaning of second, third, and further generations of biofuels, we will adopt the term advanced or next-generation biofuels. Next-generation biodiesel is a triglyceride derived fatty acid methyl ester (FAME), which does not originate from food crop sources. Additionally, there are clear limitations in some non-food crop terrestrial plant sources of triglycerides for biodiesel, such as palm oil and jatropha. Palm oil is rapidly becoming a major source of biodiesel to fulfill the European Union mandate of 10\% liquid transportation biofuels by 2010 (European Parliament, 2009). Europe is a much larger consumer of diesel fuel for passenger vehicles with approximately $50 \%$ of the passenger cars sold in the EU currently having diesel engines (Smolinska, 2008). Unfortunately, the net result of the substantial increase in demand for palm oil has been an accelerated rate of palm plantation development and deforestation in tropical ecosystems.

Another promising group of next-generation biofuels are the alcohols with longer chains than ethanol, such as butanol and branched-chain alcohols. These fuels have a higher energy density than ethanol, do not absorb water as ethanol does, and possess very favorable combustion characteristics, such as high octane ratings. These alcohols are somewhat more unusual and rare in nature, but one example of a microorganism that is adept at producing these compounds is Clostridium acetobutylicum. Regrettably, there are limitations on the use of this slow growing anaerobic organism for biofuel production. A search for other means for producing these promising longer and branched-chain alcohol biofuels in photosynthetic organisms is currently underway (Fortman et al., 2008).

While ethanol produced from cellulosic biomass is commonly touted as a promising advanced biofuel solution, the end product is still ethanol, which has all of the limitations stated above. There is strong motivation to move beyond ethanol, but what other means are available? Conversion of the sugars released by deconstruction of cellulosic biomass could easily be directed more usefully to one of the more desirable next-generation biofuels, such as microorganism-derived biodiesel or branched-chain alcohols. In a throwback to biofuels efforts of World War I, recently there has been renewed interest in the ability of Clostridial species to produce butanol and possibly other longer chain alcohol biofuels (Sillers et al., 2008). With the availability of genomes for these anaerobic bacteria, means to genetically enhance their productive capacities may be at hand. However, there are still a number of significant barriers to overcome for anaerobic fermentation to be a truly viable means of biofuel production. Alternatively, microbes such as bacteria and microalgae show promise as a renewable feedstock for a biofuels ranging from ethanol to biodiesel. The capacity of photosynthesis to capture solar energy is particularly attractive for producing renewable fuels because no intermediate chemical feedstock is required.

\section{Microalgal biomass for biofuel production}

Algae are a diverse group of aquatic, photosynthetic organisms generally categorized as either macroalgae (i.e. seaweed) or microalgae, which are typically unicellular. Although the emerging field of algal biofuels remains in its infancy, microalgae have great potential to bring the promise of clean, sustainable fuel production before we must face the reality of fossil fuel depletion and exacerbated climate change. Algae are perhaps the most effective photosynthetic organisms for generating chemical energy from sunlight - the most abundant and renewable global energy source. It is believed that a large percentage of today's fossil fuels, particularly petroleum, originated as prehistoric algal blooms. As single- 
celled organisms, microalgae are capable of producing a large portion of their biomass as small molecule biofuel precursors since they lack macromolecular structural and vascular components needed to support and nourish terrestrial plants. As such, algae provide one of the most direct routes for the photosynthetic conversion of carbon dioxide and other organic substrates to biofuel. Moreover, the large surface area to volume ratio of these aquatic microorganisms is advantageous for absorption of nutrients and sunlight, which is reflected in the rapid growth rates observed in many species.

As aquatic organisms, microalgae offer many advantages over the terrestrial bioenergy crops with which they contend. Some of the most serious drawbacks of allocating portions of existing food crops to produce biofuels, particularly ethanol from corn and biodiesel from soy or rapeseed, are the obvious competition with food production and encouragement of subsidized operations. Both outcomes are coupled with severe economic ramifications. While cellulosic ethanol may avoid the food versus fuel controversy, this technology has yet to fully mature and will likely remain at the developmental stage for a number of years. In general, terrestrial crops have relatively long growing seasons and require arable land, oftentimes supplemented with costly fertilizers that can have harmful effects on the surrounding ecosystems. Additionally, there are greenhouse gases released in the process of generating fertilizer and harvesting terrestrial biomass. Furthermore, constant irrigation of these crops is yet another impediment, as this can be taxing on natural freshwater resources. While great strides are being made toward the optimization of cellulases for enzymatic degradation of lignocellulose, a significant amount of energy is still required to harvest and pre-treat (thermochemically breakdown) the cellulosic biomass, which constitutes an additional input of fossil fuel-derived energy.

Unlike terrestrial bioenergy crops, microalgae do not require fertile land or extensive irrigation and can be harvested continuously. Several species of algae provide an alternative to freshwater use by growing in brackish, sea, and even hypersaline water. Additionally, since algae consume carbon dioxide through the process of photosynthesis, large-scale cultivation can be used to remediate the $\mathrm{CO}_{2}$ emissions from fossil fuel combustion (Benemann and Oswald, 1996) (Figure 1). Algal biomass also possesses secondary coproducts such as antioxidant pigments, edible proteins, and nutraceutical oils that other alternative fuel crops lack (Spolaore et al., 2006). Lastly, since nearly all microalgae have a simple unicellular structure, algal biomass is devoid of lignocellulose. This strong structural polymer has proven to be a significant obstacle to releasing the energy trapped in terrestrial biomass. Not only do microalgae fully address each of the disadvantages of land-based biofuel crops, but they also are amenable to genetic engineering for the enhanced biosynthesis of a wide range of advanced biofuels and high-value added products.

Currently, three fundamental objectives remain critical to the implementation of economically- and technologically-feasible algal biofuel production: [1] increase of biological productivity through species selection and genetic engineering as well as optimization of culture conditions; [2] development of low-cost vessels for cultivation, whether they be closed photobioreactors or open pond systems; and [3] improvement of inexpensive downstream processing techniques for algal biomass, including harvesting, dewatering, and extraction of biofuel metabolites (Hejazi et al., 2004a; Shelef et al., 1984; Danquah et al., 2009). As with many novel sources of bioenergy, the complexity of the microalgal biofuel production process calls for a multidisciplinary approach in which biotechnological progress will be accompanied by advances in process engineering. 


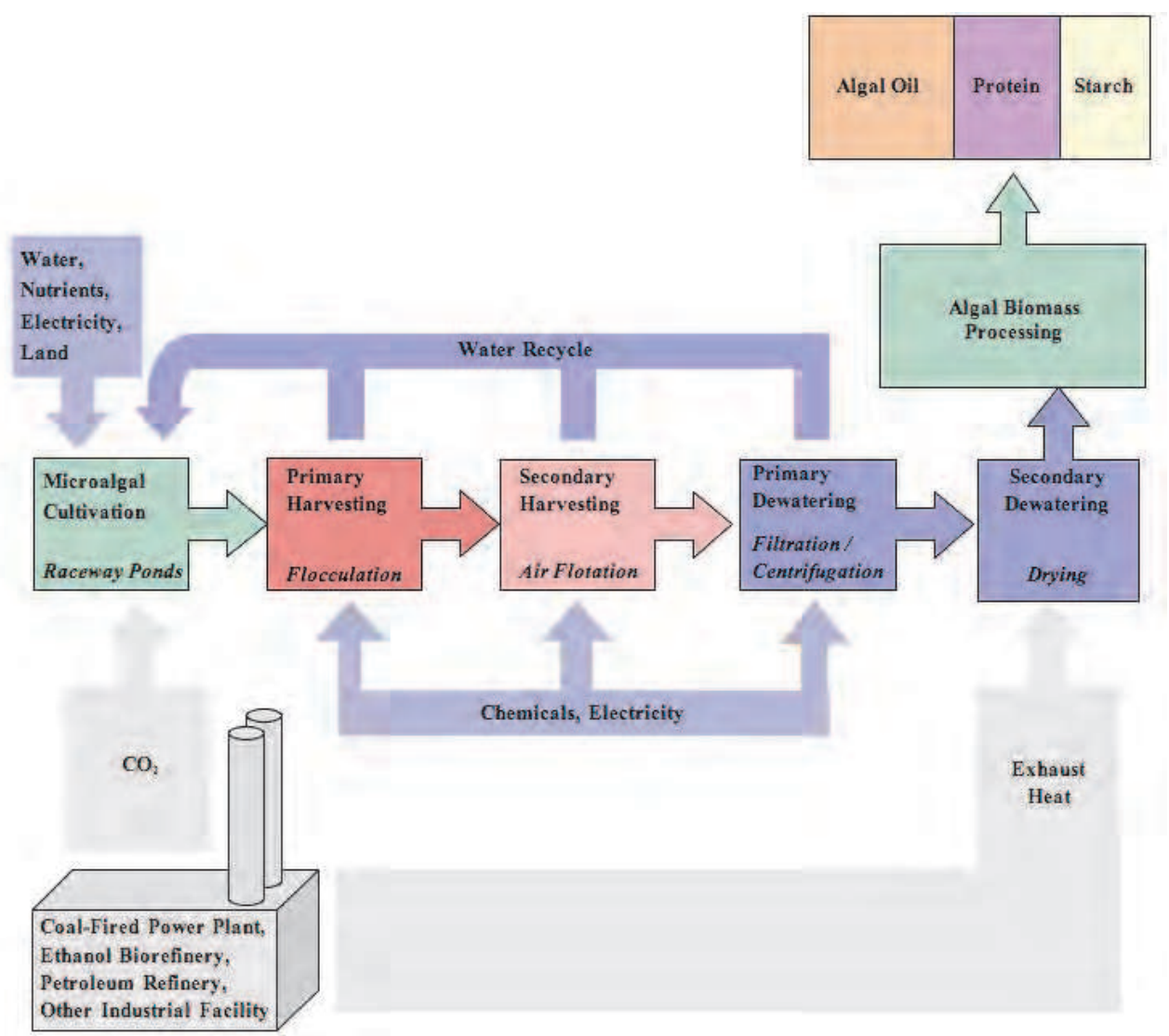

Fig. 1. Algal process flow diagram with integrated industrial $\mathrm{CO}_{2}$ sequestration.

\subsection{Commercial applicability of microalgal biofuels}

As the name 'microalgae' suggests, the relative size of these organisms may seem unsuitable for generating massive quantities of biofuel on a global scale; nonetheless, microalgae offer many advantageous qualities for biofuel production, especially when compared to terrestrial bioenergy crops. The basic principle of generating biofuel from microalgae is to exploit these cells as biological factories, whose lipid output can be as much as $70 \%$ of their total dry biomass, under optimal conditions. While many species of algae exhibit the natural capacity to produce abundant amounts of oil for conversion to biofuel, a major obstacle in the commercialization of such a process lies in the scalability. Many exciting breakthroughs in algal biotechnology have occurred on the lab bench, but mass cultivation of algae is still associated with some of the most challenging problems. A few areas of intense research focus include highly productive growth systems, temperature control, photooxidative stress tolerance, light intensity regulation, harvesting, and downstream processing. Whether it is through the manipulation of culture conditions or the application of mutagenesis and genetic engineering, the biological networks of these unicellular creatures can potentially be optimized to synthesize and/or secrete biofuel metabolites, particularly in the form of lipids 
and other hydrocarbons, in order to overcome some of the aforementioned stumbling blocks to large-scale cultivation.

It is difficult to convey a concise list of the ideal species for biofuel production because the organism must be paired not only with the climate in which it will be cultivated, but also the specific mechanism of cultivation and desired end products. Also, the lipid content can vary considerably depending on culture conditions. For example, nitrogen and silicon deprivation has shown to augment lipid accumulation in green algae and diatoms, respectively. As investigated by NREL's Aquatic Species Program, nutrient deprivation experiments and species collection and characterization efforts gave rise to an extensive list of microalgae with particularly high lipid contents (Sheehan et al., 1998).

There is, however, a serious caveat to high lipid accumulation in algae: the energy collected by the cell is partitioned into storage and, thus, made unavailable for immediate use. As a result, oleaginous species exhibit significantly slower growth rates than their more lean relatives. The fatty acid composition and growth characteristics of some of the more promising species are illustrated in Figure 2, where a clear balance can be seen between growth rate and lipid content. In this particular study, the algal species were cultivated first in airlift bioreactors, then in aerated polyethylene bags, and finally in outdoor raceway ponds for a period of four months. Subsequent biochemical evaluation found the neutral lipids to be predominantly $\mathrm{C}_{16}$ and $\mathrm{C}_{18}$, which are ideal chain lengths for the composition of biodiesel (Gouveia et al., 2009).

Astonishingly, of the thousands of different species of algae, a mere fifteen organisms are commonly used for commercial applications (Raja et al., 2008) and only eight species' genomes have been sequenced (Hallmann, 2007), but future bioprospecting endeavors paired with high-throughput screening are likely to discover more exemplary candidates for algal biofuel production.

\subsection{Opportunities for genetic engineering of algae}

While microalgae are an abundant source of naturally oil-rich biomass, these cells can also act as biological factories designed to produce of a variety of promising biofuel precursors. By elucidating the complex metabolic networks involved in carbon utilization, there lies great opportunity for genetic and metabolic engineering of these organisms. Some of the major obstacles to metabolic engineering of algae stem from the lack of basic biological knowledge of these diverse creatures, including sparse genomic information and somewhat primitive methods of genetic transformation. As a result, the introduction of nuclear transgenes to microalgal cells relies on random chromosomal integration, which is highly susceptible to gene silencing; the subsequent recovery of stable transformants is limited to only a handful of species and is oftentimes irreproducible. Overcoming these biotechnological barriers, however, will present enormous opportunities to develop microalgae as versatile platform for biofuel production.

A number of improvements in the productivity of green algae and diatoms would significantly enhance their capabilities as biofuel producers. Photoautotrophic algal growth rates and cell densities at commercial are low compared to microbial fermentation. Enhancement of growth through metabolic engineering with control of cell cycle would be a breakthrough for algal biofuels. Increasing biofuel feedstock production by improving the synthesis of biofuel precursors is imperative. Metabolic engineering of secretion pathways or developing means to readily strip hydrocarbons would allow the organism to survive while producing biofuel metabolites on a continue basis. This would reduce the amount of 
biomass that is produced per unit of biofuel, thus focusing resources on the primary product. Metabolic engineering might also increase the range of biofuel metabolites and other high-value added materials that can be synthesized. Furthermore, improved performance in a variety of photobioreactors and conditions is necessary. The development of organisms that can survive in environments that exclude invasive species and other contaminant microorganisms is another desirable attribute for open cultivation systems. Finally, the goal of designing suicide genes to prevent the unintended release of genetically modified organisms (GMOs) is an important consideration.
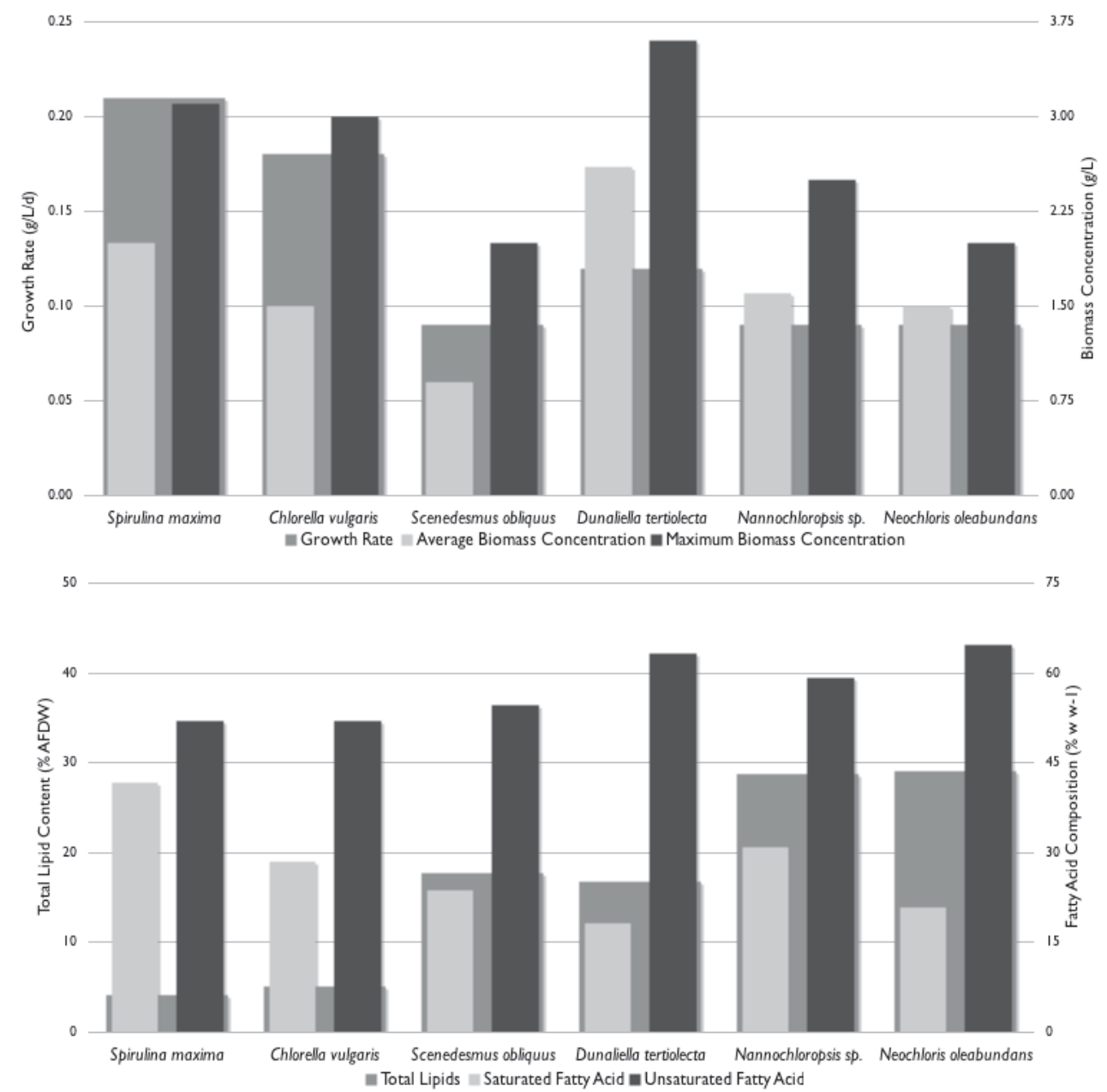

Fig. 2. Growth characteristics and lipid profiles of commercially attractive microalgae.

From a genetic engineering standpoint, there exist certain superior characteristics of eukaryotic algae as compared to other photosynthetic sources of biofuels. Focusing on green algae and diatoms will allow the transfer of well-established metabolic engineering 
approaches used in other eukaryotic systems. With eukaryotic algae there is the ability to perform both chloroplast and nuclear transformation, possibly increasing the complexity and range of metabolic engineering. Because eukaryotes have evolved a membrane bound secretory pathway, it is conceivable that eukaryotic algae could be genetically engineered to secrete lipid bodies into the media (Benning, 2008). For example, the alga Botryococcus braunii has naturally evolved this mechanism for secreting hydrocarbons. If this biological feat could be achieved in other microalgal species, it would greatly simplify downstream processing by eliminating cell harvesting and lysis; thus, reducing the entire procedure to merely skimming the lipids from the top of the medium.

Many accomplishments have already been made in the field of microalgal bioengineering (Leon-Banares et al., 2004; Walker et al., 2005), the most relevant to biofuel production being increased photosynthetic efficiency and light penetration in C. reinhardtii (Mussgnug et al., 2007), but augmented lipid production through genetic alterations has yet to be achieved. Currently, C. reinhardtii remains the workhorse of algal genetic engineering for its history as a model photosynthetic organism (Harris, 2001). The recently completed genome sequence of Dunaliella salina may be a good starting point for genetic research of algal biofuel production; however, a single species cannot be expected to serve every application. With the limited availability of genomic data for microalgae (Hallmann, 2007), exploration of transgenic algae for bioenergy demands a genome project for a model biofuel production strain. Future efforts to probe the metabolic pathways of microalgae will likely employ technologies beyond genomic analysis, such as transcriptomics, metabolomics, proteomics, and lipidomics, to examine the broader biological landscape of algal metabolism (Jamers et al., 2009; Vemuri et al., 2005).

\subsection{Mass cultivation of microalgae}

The cultivation macro- and microalgae is a well-established practice, providing ample biomass for human nutrition, commercially important biopolymers, and specialty chemicals, that dates back nearly 2,000 years (Spolaore et al., 2006). As an example, growing the gelatinous cyanobacteria Nostoc in rice patties enabled much of the Chinese population to survive famine in $200 \mathrm{AD}$ (Qiu et al., 2002). Since that time, the mass cultivation of microalgae has been commercialized for the production of either whole-cell algal nutritional supplements or nutraceutical extracts, such as $\beta$-carotene, astaxanthin, and polyunsaturated fatty acids (e.g. DHA, omega-3). In the international market, China, Japan, Australia, India, Israel, and the United States are leaders in algal production.

\subsubsection{Constraints on photoautotrophic algal biomass production}

In addition to certain biological limitations, several obstacles related to cultivation must be overcome to allow economical industrial scale-up of algal biofuel production. The conversion efficiency of solar energy to biomass by microalgae is governed, in part, by the inherent biological efficiency of photosynthesis, and largely by the effectiveness of lighttransfer in liquid cultures. Some species of algae grown heterotrophically (i.e. supplemented with carbon sources other than $\mathrm{CO}_{2}$, such as sugars) can accumulate a greater amount of lipids (Wu et al., 2006); however, the costs associated with such cultivation may limit its applicability to biofuel production. The approach of heterotrophic algal biofuel production is the model for a number of algal biofuels start-up companies. 
On the other hand, generating algal biomass for biofuels with energy directly from the sun rather than a chemical intermediate has its advantages. Microalgae essentially act as biological solar panels directly connected to biorefineries. Photoautotrophic cultivation has the added benefit of $\mathrm{CO}_{2}$ sequestration from a point source. Although current commercial raceway ponds operate with areal productivities of $2-20 \mathrm{~g} \mathrm{~m}^{-2} \mathrm{~d}^{-1}$, there remains much speculation regarding the maximum achievable algal biomass productivity. While heterotrophic modes of cultivation can yield very dense algal cell cultures, photoautotrophic cultures are not expected to exceed $60 \mathrm{~g} \mathrm{~m}^{-2} \mathrm{~d}^{-1}$. Figure 3 shows a compilation of realistic areal productivities and theoretical projections for photoautotrophic algal cultivation in open ponds (Chisti, 2007; Weyer et al., 2008; Schenk et al., 2008; Wallace, 2008).

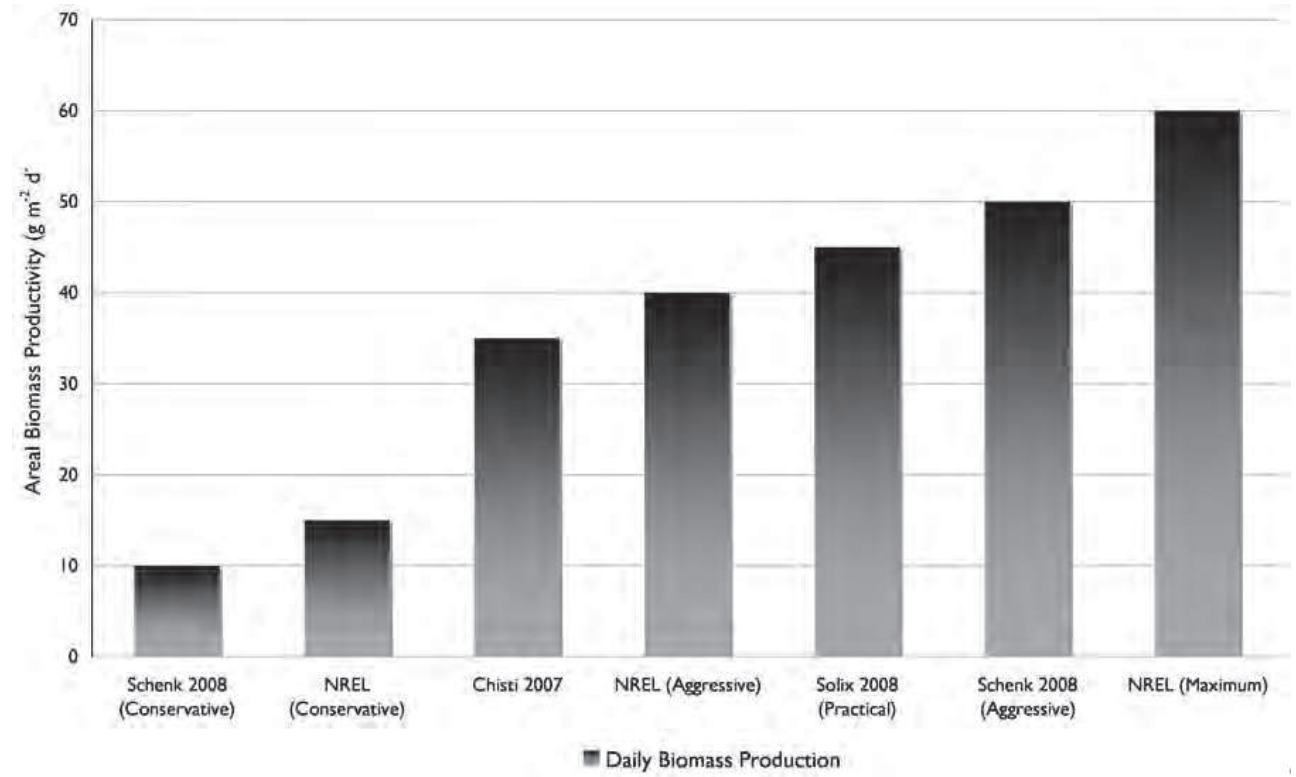

Fig. 3. Projected algal biomass productivities for raceway ponds.

While a wide range of predictions has been made for the maximum attainable productivity of algal cultures, a straightforward analysis of energy transfer in algal biomass production reveals a few key bottlenecks. By following a single photon from its origin at the sun to the desired end product of algal oil, there are a number of unavoidable losses imposed on this conversion of sunlight by the inherent bioenergetics of cellular processes. Additional diversions of solar energy can be attributed to the algal growth system and can be minimized with proper design parameters.

The first impediment that solar radiation faces when traveling to the Earth's surface is the local weather. As we know from our daily observations, cloudy skies can dramatically reduce the amount of light that reaches the ground. Additionally, while the equator receives high-intensity light year-round, solar irradiance diminishes as one travels away from the equator in latitude, thus near-equatorial zones are ideal for algal biomass production. Accordingly, Asia, Australia, and the United States are common sites for algal growth facilities. Figure 4 presents a map of solar data collected from 1990-2004 where black dots 
represent locations for which detailed weather analysis is available for algal production facilities (Weyer et al., 2008). In geographies that receive more exposure to sunlight, and accompanying high temperatures, evaporative water loss and cooling mechanisms become more important considerations.

Since there is little one can do to change the weather beyond choosing an adequate site for algal cultivation, the next constraint on solar energy collection comes from the limited spectrum of light that plants have adapted to utilize, deemed photosynthetically active radiation (PAR: $\lambda=400-700 \mathrm{~nm}$ ), which accounts for only $45 \%$ of the total energy in the visible light spectrum (Weyer et al., 2008).

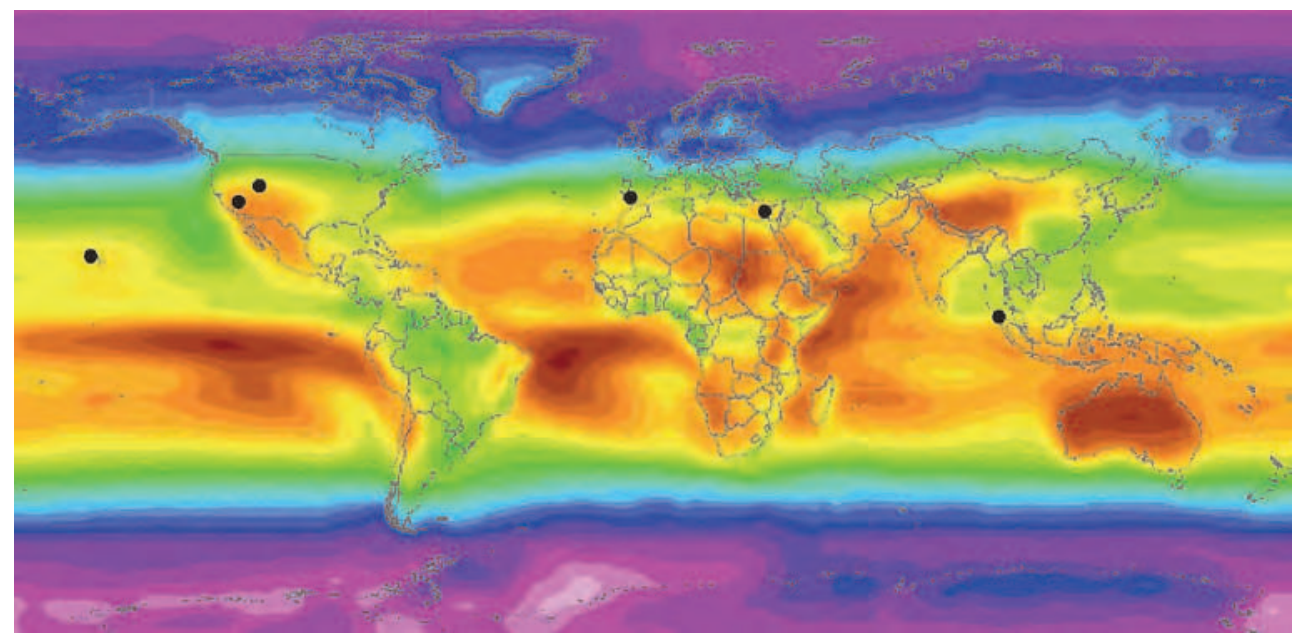

Yearly Mean of irradiance in WIm?

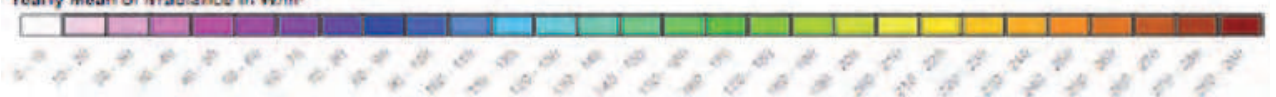

Fig. 4. Global map of average annual solar radiation (Reprinted with permission from SoDa Services, Copyright Mines ParisTech / Armines 2006).

In conventional raceway ponds and photobioreactors, incident sunlight encounters billions of algal cells as it travels through the liquid culture - each cell absorbing some of the available energy. Thus, the transmission of light is severely inhibited by cell shading in these dense solutions. For example, the leaves of a tree have evolved to be essentially twodimensional structures with only millimeter thicknesses; an algal culture volume can be thought of in a similar manner. In open ponds, only the cells on the surface are exposed to maximum sunlight, and those on the bottom of the 10-30 $\mathrm{cm}$ deep trough receive very little of this incoming energy. The advantage, though, of a liquid culture is that the shaded cells in the submerged regions can be recirculated to the surface periodically so that a large volume of biomass can be maintained. Additionally, advanced photobioreactor design can encourage optimal mixing patterns (Tredici and Zittelli, 1998).

The next hurdle that usable photons must surmount is absorption by the molecular photosynthetic apparatus. As microalgae have adapted to survive in conditions of low light, they have evolved biochemical mechanisms that are incredibly adept at collecting light energy. 
Light-harvesting complexes, which surround the photosystems in the chloroplast membrane, act as antennae to gather and shuttle photons to the photosynthetic reaction center. One limitation to complete utilization of incident PAR lies in the maximum capacity of energy that each photosystem can handle. In fact, high-intensity light can quickly inundate the photosynthetic machinery, leading to the generation of free oxygen radicals, in a process called photoinhibition (Long et al., 1994). This obviously has a negative effect on the productivity of algal cultures by leading to cellular damage and premature population demise. Unlike the natural environmental conditions to which microalgae are accustomed, industrial cultivation strives for maximum collection of solar energy. In this case, algae can be exposed to highintensity light for only a short period of time, on the scale of microseconds, allowing each photosystem to absorb light before becoming overwhelmed. Also at the biochemical level, there are inherent limitations to photosynthesis related to electron transfer. Estimates for the efficiency of photosynthesis correlate to roughly 25\% energy conversion (Weyer et al., 2008). Optimization of photosynthesis is an ambitious genetic engineering goal and is likely to remain an intrinsic parameter of algal biomass production processes.

After the available sunlight has been harnessed by photosynthesis, there exist various levels of inefficiency related to the biological conversion of this energy to biomass. Principally, nearly $40 \%$ of the total energy is required to sustain basic cellular function and growth, leaving an estimated $60 \%$ of the total photosynthetically captured energy for biomass accumulation (Weyer et al., 2008). According recent analysis utilizing actual solar irradiance and weather data from various global locations (Figure 4), and taking each of the aforementioned assumptions into account, the projected range of algal biomass production is between 38 and $47 \mathrm{~g} \mathrm{~m}^{-2} \mathrm{~d}^{-1}$ (Weyer et al., 2008), which is in agreement other predictions (Figure 3). Current values for commercial biomass production in open ponds are typically 2$20 \mathrm{~g} \mathrm{~m}^{-2} \mathrm{~d}^{-1}$, which provide sufficient profit margins for high-value products such as $\beta$ carotene, but are anticipated to meet the demands of cost-effective biofuel production in the near future. A new partnership between Seambiotic and the Israeli Electric Company has plans to produce algal biomass inexpensively for use as biofuel, with operating costs and profit margins listed in Table 1.

\begin{tabular}{lll} 
Annual Expenses (USD yr-1 & Nature Beta Technologies & Seambiotic/Israeli Electric \\
\cline { 2 - 3 } 10-ha Raceway Farm & Commercial Plant & Pilot Plant \\
Manpower & $\$ 500,000$ (20 Employees) & $\$ 120,00$ (8 Employees) \\
Electricity & $\$ 180,000$ & $\$ 30,000$ \\
Nutrients & $\$ 36,000$ & $\$ 36,000$ \\
Land & $\$ 50,000$ & $\$ 10,000$ \\
Carbon Dioxide & $\$ 150,000$ & $\$ 5,000$ \\
Sea Water & $\$ 200,000$ & $\$ 5,000$ \\
Fresh Water & $\$ 20,000$ & $\$ 10,000$ \\
Miscellaneous Expenditures & $\$ 30,000$ & $\$ 20,000$ \\
Total & $\$ 1,166,000$ & $\$ 236,000$ \\
Revenue & & \\
Biomass Production $\left(\mathrm{yr}^{-1}\right)$ & 70 tons (at 2 $\left.\mathrm{g} \mathrm{m}^{-2} \mathrm{~d}^{-1}\right)$ & 700 tons (at 20 $\left.\mathrm{g} \mathrm{m}^{-2} \mathrm{~d}^{-1}\right)$ \\
Biomass Cost (USD kg-1) & $\$ 17.00$ & $\$ 0.34$ \\
Market Price (USD kg $\left.{ }^{-1}\right)$ & $\$ 4,000($ D. salina $\beta$-carotene) & $<\$ 0.50$ (Potential Biofuels)
\end{tabular}

Table 1. Cost analysis of microalgal biomass production facilities in Israel (Reprinted with permission from Dr. Ami Ben-Amotz). 


\subsubsection{Raceway pond systems and photobioreactors}

Although primitive in design, open raceway ponds are still the predominant algaculture system for high-value added products and have been used for decades (Benemann and Oswald, 1996; Sheehan et al., 1998). The fact that raceway ponds are uncomplicated makes them less productive and offers little control over the culture parameters; however, the low cost of this low-tech cultivation system allows it to compete with complex photobioreactors (Gordon et al., 2007). The surface-to-volume ratio and corresponding light penetration in open ponds are not ideal. As a result, ponds can only support low culture densities; however, the ease of scaling production to industrial proportions ( $>1$ million liters per acre) justifies their seemingly low efficiency. The use of raceway ponds is also vindicated by their uncomplicated design, which makes them readily available for implementation and relatively simple to clean and maintain. While open ponds are cost effective, they do have a large footprint and contamination by local algal species and threat of algal grazers pose serious risks. Invasion by indigenous microorganisms may be protected against by the use of greenhouse enclosures or by growing algae that can withstand hypersaline environments, such as Dunaliella salina. For the purpose of biofuel production, however, the low areal productivities of ponds alone may not be able to provide the necessary biomass feedstock economically. Commercial scale microalgal biofuel facilities will likely rely on integrated systems of high efficiency photobioreactors to provide a dense inoculum for readily scalable raceway ponds (Huntely et al., 2007).

While genetic engineering approaches may improve the photosynthetic and biosynthetic capabilities of microalgae, many innovative methods exist for optimizing photoautotrophic culture conditions to accomplish the same goal of increased yield (Muller-Feuga, 2004). The breadth of chemical engineering knowledge being applied to photobioreactor (PBR) design in order to enhance light and nutrient availability represents an important advance in the field (Tredici and Zittelli, 1998; Miron et al., 1999), particularly for modular and scalable reactors (Janssen et al., 2003; Hu et al., 1996); however, the cost of these technologies remains the ultimate constraint on feasibility.

Photobioreactors aim to optimize many, if not all, of the culture parameters crucial to microalgal growth. One condition achieved in PBRs, but not raceway ponds, is turbulent flow to produce enhanced mixing patterns. By simply increasing the Reynolds number of these systems, the resulting fluid dynamics have a positive effect on nutrient mass transfer, light absorption, and temperature control (Ugwu et al., 2008). However, highly turbulent flow within complex geometries comes at the expense of the cells' sensitivity to shear stress, which is one limitation of photobioreactor design. Another important consideration is the time scale over which the microalgae are transferred from the periphery of the bioreactor to the interior shaded region, as there exists a limit to the amount of light the cells can process before photoinhibiton occurs.

One of the most beneficial aspects of photobioreactors is the extended surface area achievable with tubular and flat-panel designs. This route to increased productivity takes advantage of allowing more algae to have contact with sunlight than an area of land would regularly allow with more basic cultivation systems; however, the additional cost of maintaining ideal temperatures and protecting these sometimes delicate devices from inclement weather pose some concern. Many of these nascent technologies depend entirely on the site of deployment and, as a result, require a great deal of customization (Janssen $e t$ al., 2003; Miron et al., 1999). 
Some additional drawbacks of photobioreactors include the chemical gradients that can develop, particularly along tubular reactors. As a result of photosynthesis, a significant amount of oxygen can accumulate in these tubes and must be purged periodically. High concentrations of oxygen can both inhibit photosynthesis and, when combined with high irradiance, result in the formation of reactive oxygen species (ROS) (Tredici and Zittelli, 1998). These added difficulties contribute to the higher complexity and cost of photobioreactor operation. Some low-cost alternatives include vertical-column or hangingbag bioreactors, which still provide a closed system for monocultures, with less control over culture parameters. These systems often rely on sparged air to provide both $\mathrm{CO}_{2}$ and mixing force, as in airlift bioreactors. The ability to strike a balance between cost and productivity is the major challenge of microalgal cultivation, especially for applications that require closed cultivation, as is the case with genetically modified microalgae.

\section{Toward the development of selectable markers for Dunaliella salina}

In the academic community, green microalgae serve as model organisms for photosynthetic research; Chlamydomonas reinhardtii is the most reputable species for this work (Harris, 2001). Volvox carteri, a multicellular microalga, is another well-established model species for the elucidation of the genetic basis of cellular differentiation (Miller, 2002). In recent years, the green alga Dunaliella salina has been utilized to complement the study of photosynthesis, osmoregulation, carotenogenesis, and glycerol production (Jin et al., 2001; Liska et al., 2004; Thompson, 2005; Shaish et al., 1992; Chitlaru et al., 1991). Dunaliella salina is an attractive platform for both commercial and academic pursuits owing to its intriguing and advantageous abilities to survive in conditions of extreme salinity and produce significant amounts of $\beta$-carotene. Currently, the aspiration to genetically and metabolically engineer this organism in order to probe its biological networks and eventually enhance its productivity is an ambitious goal. Until recently, the stable expression of transgenes by this organism has been limited due to inexperience with genetic transformation and insufficient knowledge of the species' genome. While molecular methods of manipulation make $C$. reinhardtii and $V$. carteri experimentally tractable at many levels, there is a pressing need for the same tools to be developed for $D$. salina.

This section discusses attempts to genetically engineer $D$. salina through the development of selectable marker systems. The investigation includes detailed characterization of the growth response of $D$. salina to a number of antibiotics and herbicides commonly used for selection of microalgae, such as bleomycin, paromomycin, and phosphinothricin (PPT). Based on reported genetic sequence information for $D$. salina, promoter and 3'-UTR regions of highly active genes were selected as targets for genomic PCR, with the hopes of creating D. salina-specific plasmid transformation vectors. Although these efforts did not yield the intended results, this work establishes a foundation for genetic engineering of $D$. salina, which is expected to continue now that the sequenced genome has been made available (Smith et al. 2010).

\subsection{D. salina as a platform organism for biotechnological development}

For decades, $D$. salina has been cultivated for its natural ability to produce $\beta$-carotene. This valuable bioproduct allows for large-scale cultivation and processing of the biomass to be very profitable, as $D$. salina is the predominant source of natural $\beta$-carotene (Ye et al. 2008). This green alga is ideal for growth in outdoor ponds due to its ability to grow in high 
salinity waters - as much as eight times the salt concentration of seawater - greatly reducing the threat of contamination by local microbes and eliminating the need for large quantities of freshwater. Dunaliella spp. are similar to Chlamydomonas spp. in that they exist as single, flagellated, elongated cells in the size range of 10 microns; however, D. salina and $D$. tertiolecta, are capable of osmoregulation by a complex network of ion channels, a flexible cell membrane uninhibited by a cell wall, and glycerol biosynthesis to offset osmotic pressure (Goyal, 2007). As such, the lack of a rigid cell wall makes the algal biomass relatively simple to lyse for the purpose of downstream processing. Furthermore, the technique of "milking" microbial cells for certain metabolites has improved substantially in recent years. In this process, the cells are contacted with a biocompatible organic solvent in order to promote preferential transfer of desired compounds to the solvent phase, leaving the cells viable for continued bioproduction. This process has been successfully demonstrated with $D$. salina for the extraction of $\beta$-carotene in a two-phase system (Hejazi et al., 2004b).

While the demand for natural $\beta$-carotene dictates the high market price of this compound and continued use of $D$. salina, an increasing desire for biofuel production draws an inquisitive eye to the carotenogenesis pathways of D. salina (Lamers et al., 2004). Since all carotenoid compounds are composed of long-chain branched hydrocarbons, it is conceivable that the biosynthetic pathways of $D$. salina could be altered to produce hydrocarbons that are ideal for use as gasoline-like biofuel. With some molecular biology tools already developed for Dunaliella spp. (Polle et al., 2009), the sequencing and annotation of its $610 \mathrm{Mbp}$ nuclear genome will now allow for more extensive genetic engineering endeavors with this organism. At the time of these experiments, only the chloroplast and mitochondrial genomes of $D$. salina CCAP 19/18 (GenBank GQ250046, GQ250045) were released. In light of its unique biotechnological application and long history of mass production, $D$. salina is an ideal organism for future development as a biofuel producing microalgae.

\subsection{Genetic engineering of $D$. salina}

Owing to the attractiveness of $D$. salina for biotechnology, there is a renewed interest in engineering this organism. Publications have reported the genetic transformation of $D$. salina by both microparticle bombardment and electroporation (Geng et al., 2003; Tan et al., 2005). Some of the most impressive progress in the field has come from the Xue group at Zhengzhou University in China. With research covering optimization of transformation techniques, gene characterization, and enhanced gene expressing utilizing matrix attachment regions, their work provides important information and an exemplary research path to follow toward genetic engineering of D. salina (Wang et al., 2009; Lu et al., 2009; Jia et al., 2009a; Feng et al., 2009; Wang et al., 2007; Jia et al., 2009b; Liu et al., 2005; Jiang et al., 2003). The down-regulation of specific genes using RNAi in D. salina has also been reported (Jia et al., 2009a; Sun et al., 2008). These advances, however, are not readily reproducible and represent solitary accomplishments with an alga that has otherwise been difficult to transform.

\subsubsection{Selective agents and genes conferring antibiotic resistance}

The bleomycin family of glycopeptide antibiotics is toxic to a wide range of organisms with as intercalator functionality able to cleave DNA. Bleomycin-resistance, attributed to the ble gene, is an ideal selectable marker as the BLE protein acts in stoichiometric equivalent. Occurring as a dimer, each protein has a strong affinity for binding and inactivating two 
molecules of bleomycin. Therefore, the level of expression of this exogenous gene can be directly correlated with antibiotic tolerance observed phenotypically. As such, it has been developed as a selectable marker system for nuclear transformation of C. reinhardtii and $V$. carteri and is likely to have similar applicability in other algae (Lumbreras et al., 1998; Hallmann et al., 1999). Since the protein must enter the nucleus, it requires high levels of expression to be active; thus, inherently selecting for clonal isolates with high-level expression. Commercial forms of bleomycin include bleocin ${ }^{\mathrm{TM}}$ and zeocin ${ }^{\mathrm{TM}}$, which are known to affect mammalian, insect, yeast, bacterial, and plant cells.

Paromomycin has been used extensively as a selective agent for the genetic engineering of microorganisms as well as an antibiotic for the treatment of bacterial infections in humans. Paromomycin acts by binding to the $16 \mathrm{~S}$ ribosomal RNA of microbes, effectively interfering with protein synthesis. The aminoglycoside 3'-phosphotransferase gene aph from Streptomyces rimosus already exists in a codon bias similar to that of Chlamydomonas and confers resistance to paromomycin, kanamycin, and neomycin. Paromomycin is highly toxic to green algae and has been used as an effective selective agent in both $C$. reinhardtii and $V$. carteri (Sizova et al., 2001; Jakobiak et al., 2004).

Phosphinothricin (PPT), also known as glufosinate-ammonium (GLA) and bialaphos, is a natural amino acid that competitively inhibits glutamine synthesis in plants and animals (Hoerlein, 1994). For this reason, it is used in a number of herbicides, including Basta ${ }^{\circledR}$ and RoundUp ${ }^{\circledR}$. A number of agricultural crops have been engineered by to resist PPT through introduction of the bar (bialaphos resistance) gene from Streptomyces hygroscopicus, which encodes a phosphinothricin acetyl transferase (Thompson et al., 1987). In the academic community, PPT is used as a selective agent for work with Arabidopsis and the bar gene is carried on pGR117 for Agrobacterium-mediated transformation of A. thaliana (Akama et al., 1995).

\subsubsection{Endogenous $D$. salina genetic regulatory elements}

Prior to the availability a fully sequenced genome, the genetics of $D$. salina were explored for useful elements such as regulatory sequences of highly expressed genes. Highly active endogenous promoter and 3'-untranslated region (UTR) pairs are of particular interest and significance to expressing transgenes in Dunaliella. Recent publications describing the use of the actin, rbcS, carbonic anhydrase, and ubiquitin promoters (Jiang et al., 2005; Walker et al., 2004; Chen et al., 2009) and nitA 3'-UTR (Li et al., 2007; Xie et al., 2007) are the basis for many of the pioneering attempts to genetically engineer $D$. salina, including the work presented hereafter.

\subsection{Materials and methods \\ 3.3.1 Microalgal cell culture}

D. salina strains CCAP 19/18 and UTEX 1644 were obtained from the Culture Collection of Algae and Protozoa (UK) and the Culture Collection of Algae at University of Texas at Austin, respectively, and maintained on sterile agar plates $(1.5 \% \mathrm{w} / \mathrm{w})$ containing $1 \mathrm{M} \mathrm{NaCl}$ Dunaliella medium (Weldy et al., 2007). Cells were cultivated photoautotrophically in 1-L glass Fernbach flasks at $27^{\circ} \mathrm{C}( \pm 1)$ using $1 \mathrm{M} \mathrm{NaCl}$ Dunaliella medium (DM). Each axenic batch culture was inoculated with $10 \mathrm{ml}$ of exponentially growing cells $\left(1 \times 10^{6}\right.$ cells ml-1), constantly stirred, bubbled with sterile air, and illuminated with cool-white fluorescent bulbs at an intensity of $80 \mu \mathrm{E} \mathrm{m}^{-2} \mathrm{~s}^{-1}$. 


\subsubsection{Generation of dosage response curves}

In order to test the efficacy of the antibiotics bleocin ${ }^{\mathrm{TM}}$ (EMD Biosciences), paromomycin (MP Biomedicals), and the PPT-containing (200 $\left.\mathrm{g} \mathrm{L}^{-1}\right)$ commercial herbicide Basta ${ }^{\circledR}$ (Bayer CropSciences) on D. salina CCAP 19/18, algal cells were grown in the presence of various concentrations of each selective agent (Table 3) using 100-ml stirrer flasks under the same conditions mentioned previously, with the exception of aeration. Each culture was inoculated with $10 \mathrm{ml}$ of exponentially growing cells $\left(1 \times 10^{5}\right.$ cells ml$\left.^{-1}\right)$ and the cell density was measured with a Zeiss Axiovert 100 inverted light microscope using a hemocytometer over a one week period. Additionally, cells were plated on agar to analyze viability on solid medium. Measurements were taken in duplicate and experiments were repeated two times.

\subsubsection{Molecular cloning and construction of vectors}

All plasmids were prepared and isolated from bacterial hosts using the QIAPrep Kit (Qiagen) following the supplier's protocol. E. coli DH5a cells (Invitrogen) were grown axenically either on LB agar or in LB medium containing pertinent antibiotic selective pressure (ampicillin or kanamycin) at $37^{\circ} \mathrm{C}$. Genomic DNA was extracted from D. salina using standard CTAB protocol adapted from Volvox carteri. PCR was performed using the MJ Mini (Bio-Rad) to amplify the actin (GenBank: AF541875) and rubisco small subunit (GenBank: AY960592) promoters and nitA 3'-UTR (GenBank: EF156403) from D. salina UTEX 1644 genomic DNA. Likewise, the genes ble and bar were amplified from the plasmids pSP124 and pGR117, respectively. All primers employed in this study are listed below in Table 2. Each PCR product was subsequently ligated into the subcloning plasmid pGEM ${ }^{\circledR}-\mathrm{T}$ Easy (Promega) using T4 DNA Ligase and its corresponding buffer (Invitrogen). Sequencing of the genetic fragments derived from PCR was performed at the UMBC Biological Sciences Dept. DNA sequencing facility using BigDye ${ }^{\circledR}$ (Applied Biosystems).

\begin{tabular}{ll} 
Target Sequence & Primers (including NotI, SmaI, HindIII, and Xhol for subcloning) \\
\hline actin promoter & 5'-AATAATAGCGGCCGCCACGGCTCACCATCTTGTTT-3' \\
& 5'-AATAATACCCGGGTTGATCTCTCTGTCACCCCT-3' \\
\hline rbcS2 promoter & 5'-AATAATAAGCGGCCGCAGACATGAACCTATA-3' \\
& 5'-AATAATAACCCGGGAGGTCTTGGCAATGA-3' \\
\hline bar & 5'-AATAATACCCGGGATGAGCCCAGAACGACGCCC-3' \\
& 5'-AATAATAAAGCTTTCAGATTTCGGTGACGGGCA-3' \\
\hline ble & 5'-AATAATACCCGGGATGTTCTTTACTTTTTTACA-3' \\
& 5'-AATAATAAAGCTTCTAGAGTGGGTCGACGTCGG-3' \\
\hline aphVIII & 5'-AATAATACCCGGGCGAAGCATGGACGATGCGTT-3' \\
& 5'-AATAATAAAGCTTTCAGAAGAACTCGTCCAACA-3' \\
\hline nitA 3'-UTR & 5'-AATAATAAAGCTTGCGGGGTCAGCAGGAGCGAC-3' \\
& 5'-AATAATACTCGAGTCGATCAGCCTTTGCAATCC-3' \\
\hline
\end{tabular}

Table 2. Primers used to amplify genes and promoters for vector development.

\subsubsection{Genetic transformation of $D$. salina}

\section{Electroporation}

A population of D. salina CCAP 19/18 cells was harvested from a 250-ml culture in its

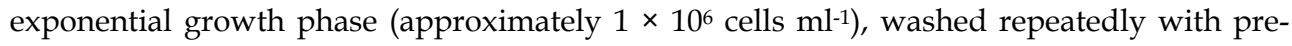


electroporation buffer $(0.2 \mathrm{M}$ mannitol, $0.2 \mathrm{M}$ sorbitol) to remove residual salts, and resuspended in electroporation buffer $\left(0.08 \mathrm{M} \mathrm{KCl}, 0.005 \mathrm{M} \mathrm{CaCl}_{2}, 0.01 \mathrm{M} \mathrm{HEPES,} 0.2 \mathrm{M}\right.$ mannitol, $0.2 \mathrm{M}$ sorbitol) to achieve a final density of $8 \times 10^{7}$ cells ml-1 (Sun et al., 2005). Next, $500 \mu \mathrm{l}$ electroporation samples were prepared in $0.4 \mathrm{~cm}$ electrode gap cuvettes (Bio-Rad), which contained either $4 \times 10^{7}$ or $1 \times 10^{6}$ cells ml-1, $20 \mathrm{mg} \mathrm{ml}^{-1}$ of pSP124, and $2 \mathrm{mg} \mathrm{ml}^{-1}$ of herring or salmon sperm DNA (Sigma). After a 10 minute incubation on ice, electroporation was executed using the Gene Pulser ${ }^{\circledR}$ II with Capacitance Extender Plus (Bio-Rad). Two electroporation conditions were tested, which correspond to the following respective parameters: [1] capacitance of $500 \mu \mathrm{F}$ and voltage of $400 \mathrm{~V}\left(1 \mathrm{kV} \mathrm{cm}^{-1}\right)$ and [2] capacitance of $25 \mu \mathrm{F}$ and voltage of $1.6 \mathrm{kV}\left(4 \mathrm{kV} \mathrm{cm}^{-1}\right)$; the resistance of each sample was $50 \Omega$. Following the electric pulse, the cells were immediately supplemented with DM and allowed to recover in the dark for 12 hours at room temperature. For subsequent selection of potential transformants, the cells were plated on 1.5\% agar DM plates containing $4 \mathrm{mg}^{\text {bleocin } \mathrm{L}^{-1} \text { and }}$ monitored for a one week period.

\section{Microparticle Bombardment}

Spherical gold particles of less than $10 \mu \mathrm{m}$ in diameter (Aldrich) were prepared by repeatedly washing with and resuspending in sterile $\mathrm{dH}_{2} \mathrm{O}$ to achieve a concentration of 50 $\mathrm{mg} \mathrm{ml}-1$. For twenty shots from the microparticle gun, approximately $20 \mu \mathrm{g}$ of DNA was ethanol-precipitated onto $12.5 \mathrm{mg}$ of gold particles $(250 \mu \mathrm{l})$ for one hour at $-80^{\circ} \mathrm{C}$. After briefly spinning the gold solution at 14,000 RPM, the pellet was washed with $70 \%$ ethanol, spun again, and finally resuspended in $78 \%$ ethanol and kept on ice for use with the transformation gun.

Just before transformation, a 1-L D. salina CCAP 19/18 culture in exponential phase (approximately $1 \times 10^{6}$ cells $\mathrm{ml}^{-1}$ ) was collected by centrifugation (Sorvall ${ }^{\circledR}$ RC-5B Refrigerated Superspeed Centrifuge, Du Pont Instruments) at 5,000 RPM for 10 minutes at $25^{\circ} \mathrm{C}( \pm 5)$ and resuspended in $5 \mathrm{ml}$ of fresh DM. Cell bombardment and recovery were as described previously for transformation of Volvox (Schiedlmeier et al., 1994). Each filter paper was then submerged in $25 \mathrm{ml}$ of $\mathrm{DM}$ and allowed to recover without antibiotic selective pressure for two days using the culture conditions mentioned previously, with the exception of aeration, and transformed colonies were subsequently selected for using the minimum inhibitory concentration (M.I.C.) of the appropriate agent on solid medium.

\subsection{Results}

\subsubsection{Determination of minimum inhibitory concentrations}

In liquid culture, the growth rate of D. salina CCAP 19/18 was significantly retarded by a

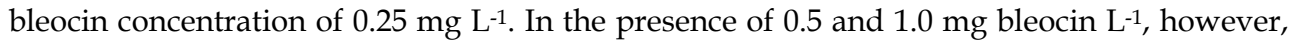
growth was completely inhibited; yet, cells were able to survive for over a week. In accordance with this restricted cell division, these cells exhibited physical manifestations of stress including minimal chlorophyll pigmentation and reduced motility. Of most relevance to the current study, bleocin concentrations of $2.0 \mathrm{mg} \mathrm{L}^{-1}$ and higher proved to eventually eradicate the algal cultures, although some viable cells persisted for three to five days. Similar results were observed when $D$. salina was cultivated on solid medium containing comparable concentrations of bleocin; however, the rate of growth on agar plates was expectedly much slower. An appreciable number of $D$. salina colonies were able to survive

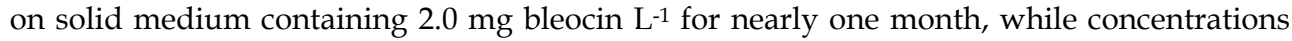


of $4.0 \mathrm{mg}$ bleocin $\mathrm{L}^{-1}$ and higher killed the cells within one week. Growth curves for liquid cultures that exhibited prolonged viability $\left(0.25,0.5,1 \mathrm{mg} \mathrm{L}^{-1}\right)$ are depicted in Figure 5. Based on these findings, the M.I.C. of bleocin for this microalgal strain were found to be 2.0 $\mathrm{mg} \mathrm{L}^{-1}$ in liquid culture and $4.0 \mathrm{mg} \mathrm{L}^{-1}$ on solid medium. Both conditions of selection require at least one week of exposure to the respective M.I.C. of bleocin.

The commercial herbicide Basta ${ }^{\circledR}$, which employs PPT as its active ingredient, proved to be the most potent and fastest-acting selective agent tested. PPT concentrations of $1 \mathrm{mg} \mathrm{L}^{-1}$ and higher were able to kill $D$. salina cells within a matter of hours. In the presence of $0.5 \mathrm{mg}$ PPT $\mathrm{L}^{-1}$, the growth rate was essentially negligible and these cultures were not sustainable for more than three days. Lastly, although $0.25 \mathrm{mg} \mathrm{PPT} \mathrm{L}^{-1}$ reduced the rate of cell division, cultures remained viable for over a week. This concentration of PPT also induced noticeable signs of toxicity such as inhibited motility and increased carotenoid pigmentation in the algae. On solid medium, D. salina was significantly more tolerant to PPT than in liquid culture. Cells survived on agar plates containing $0.25,0.5$ and $1.0 \mathrm{mg} \mathrm{L}^{-1}$ for over one month. Qualitatively, an inhibition of cell growth was reflected both in the relative number of surviving cells, which naturally was inversely proportional to PPT concentration, as well as the prolonged viability of these slower growing colonies due to their more gradual exhaustion of available nutrients. After one month, the cells were rich in $\beta$-carotene and noticeably orange in color. Figure 6 shows a side-by-side comparison of $D$. salina spot tested on $1 \mathrm{M} \mathrm{NaCl}$ medium with no selective agent added (left) and $0.25 \mathrm{mg}^{\text {PPT L-1 }}$ (right). The threshold for complete cell death on solid medium was clearly crossed at a PPT concentration of $2.0 \mathrm{mg} \mathrm{L}^{-1}$ after one week.

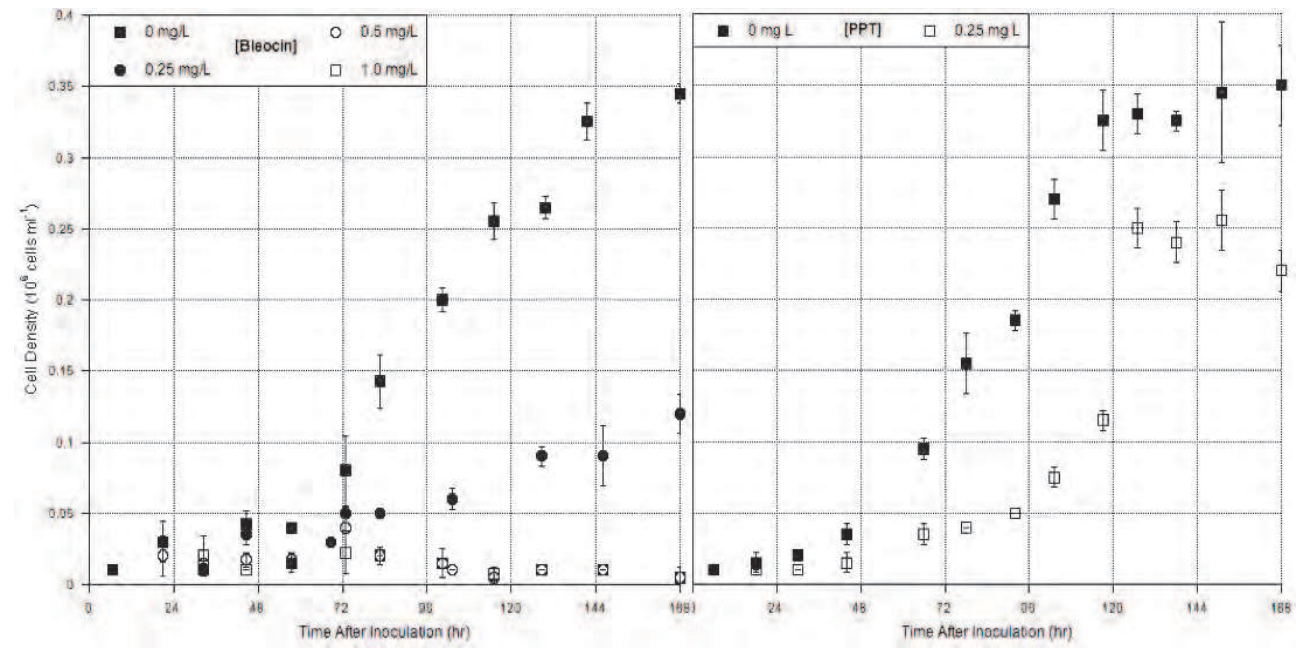

Fig. 5. Dosage response curves for D. salina CCAP 19/18.

While paromomycin is toxic to related microalgae, D. salina CCAP 19/18 was found to be remarkably insensitive to this antibiotic. In the presence of concentrations as high as $400 \mathrm{mg}$ paromomycin $\mathrm{L}^{-1}$, the algal cells were able to proliferate vigorously. Consequently, paromomycin was deemed unsuitable as a selective agent for the genetic transformation of D. salina. 


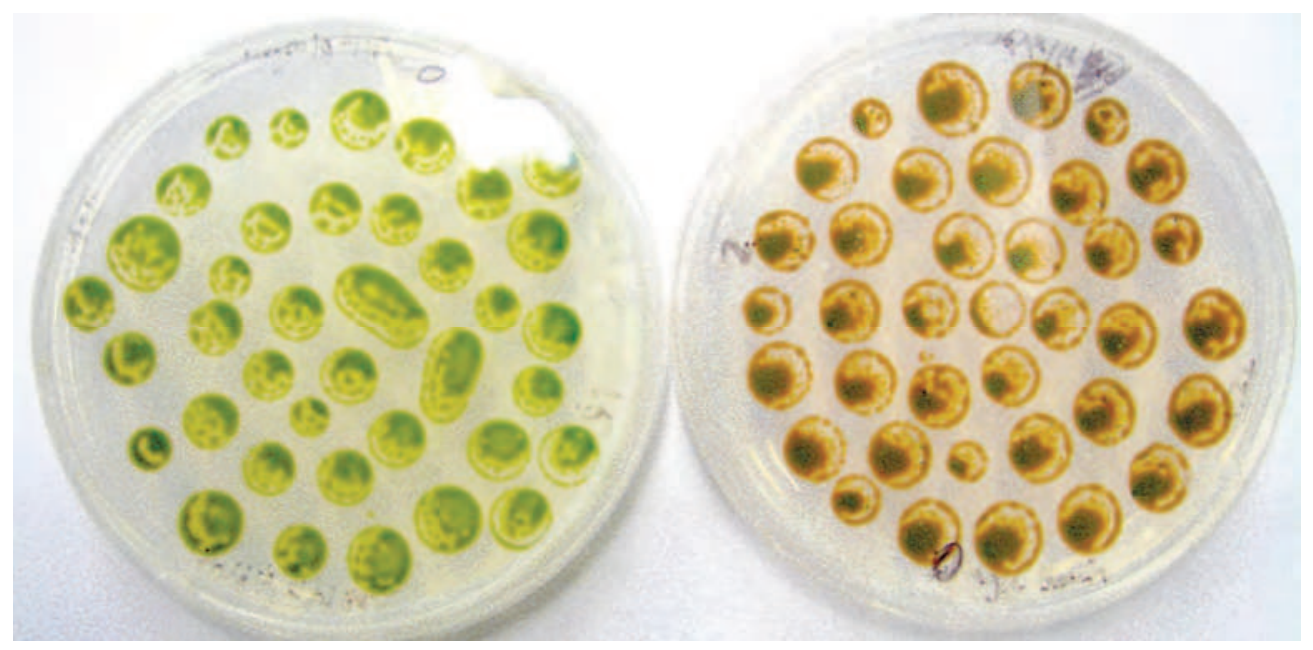

Fig. 6. Stress-induced accumulation of $\beta$-carotene by $D$. salina.

\begin{tabular}{ccc}
\hline [Bleocin] mg L-1 & Growth Rate (Liquid) & Cell Viability (Solid) \\
\hline 4.0 & $\times$ & $\times$ \\
3.0 & $\times$ & - \\
2.0 & $\times$ & + \\
1.0 & 0 & + \\
0.5 & 0 & + \\
0.25 & - & + \\
0 & + & + \\
\hline [Phosphinothricin] mg L-1 & Growth Rate (Liquid) & Cell Viability (Solid) \\
\hline 4.0 & $\times$ & $\times$ \\
3.0 & $\times$ & $\times$ \\
2.0 & $\times$ & $\times$ \\
1.0 & $\times$ & + \\
0.5 & $\times$ & + \\
0.25 & - & + \\
0 & + & + \\
\hline Paromomycin] mg L-1 & Crowth Rate (Liquid) & + \\
\hline 400 & + & + \\
300 & + & + \\
200 & + & + \\
100 & + & + \\
50 & + & + \\
0 & + & + \\
\hline
\end{tabular}

Table 3. D. salina CCAP 19/18 growth response to antibiotic and herbicide exposure characterized as either normal (+), inhibited (-), or negligible (0). Concentrations that engendered death of the entire algal population within one week are denoted with an $\times$. 


\subsubsection{Probing the $D$. salina genome for constitutively active promoters}

Despite others' success with genomic PCR of Dunaliella-specific nucleotide sequences, our efforts to obtain the actin and $r b c S 2$ promoters and nitA 3'-UTR were unsuccessful. Although the products from these PCR attempts appeared to be the correct fragment length, upon sequencing, it became clear that these were not the targets that we set out to amplify. BLAST analysis of some sequences recovered showed relevant homology to genes from Dunaliella viridis and Arabidopsis lyrata, but not the targeted promoters specific to D. salina.

\subsection{Discussion}

The inefficacy $D$. salina promoter and 3'-UTR amplification greatly inhibited our efforts to develop and test genetic transformation techniques with this alga. The failed attempts to amplify the actin, rbcS2, and nitA regulatory elements raises some concern for the accuracy of the sequences deposited in GenBank. Another possible cause for this lack of success might come from the strain of $D$. salina used as a source for these sequences. All of the prior work with these promoters and 3'-UTR has been done using the UTEX 1644 D. salina strain. It is conceivable that the UTEX 1664 sample supplied to us was either misidentified or contaminated. Additionally, the published sequence information might not have actually come from UTEX 1644, as claimed. From our observations, the CCAP 19/18 strain was consistently able to produce $\beta$-carotene when cells accumulated and dried on the inner surface of the culture flasks, unlike UTEX 1644. Although, the only way to know the identity of each strain for certain would be to perform genomic analysis of the $18 \mathrm{~S}$ rRNA. This technique has been established for many species of Dunaliella, including both the UTEX 1664 and CCAP 19/18 strains (Olmos et al., 2000; Polle et al., 2008).

Due to our inability to construct Dunaliella-specific expression vectors, the attempts to genetically transform $D$. salina were limited to the use of the $C$. reinhardtii bleomycinresistance plasmid, pSP124. There is evidence that genetic regulatory sequences from $D$. salina demonstrate activity in C. reinhardtii (Walker et al., 2004); thus, it is possible that the same is true of C. reinhardtii promoters for use in D. salina. Unfortunately, after numerous trials of electroporation and microparticle bombardment, no viable transformants were recovered after selection on bleocin plates.

It was surmised that the force of impact imposed by gold microparticles would be too much for D. salina, which lacks a cell wall; however, electroporation should have been more accommodating. Testing both high and low voltage (4 and $\left.1 \mathrm{kV} \mathrm{cm}^{-1}\right)$ electroporation conditions as well as high and low cell densities $\left(4 \times 10^{7}\right.$ or $1 \times 10^{6}$ cells $\left.\mathrm{ml}^{-1}\right)$ for transformation proved unacceptable for even transient expression of the ble gene. We did find that, with both methods of transformation, control samples remained viable after the procedure, so at least the electrical pulse itself was not killing the cells. Without endogenous D. salina promoters, we are unable to determine whether the absence of transgene expression was a result of improper transformation conditions or inactive promoters.

Notwithstanding the pitfalls encountered during the molecular work with $D$. salina, experiments pertaining to antibiotic and herbicidal tolerance yielded results that will complement the microbiological understanding of D. salina and aid with future genetic manipulation of the organism.

\subsection{Conclusions}

Our approach to genetic transformation of a Dunaliella salina will hopefully set the stage for future efforts toward genetic engineering of this organism and, perhaps, act as a template 
for genetic bioprospecting with other novel algal species. Based on our dosage response experiments, we were able to narrow down the already short list of selective agents applicable to $D$. salina to the antibiotic bleomycin and the herbicide phosphinothricin and quantify the minimum inhibitory concentrations in both solid and liquid medium.

Limited by insufficient sequence information, we were unable to construct the proposed $D$. salina transformation vectors and transformation with existing Chlamydomonas vectors proved to be unsuccessful. Dunaliella salina is known to be a delicate organism due to its lack of a cell wall; thus, established transformation techniques may be too forceful for this organism. It is also reasonable to believe that gene silencing is an issue in D. salina and, in addition to optimizing transformation protocols suitable for this alga, molecular methods for promoting stable transgene integration and expression are of great interest to continued work in with Dunaliella species.

Although some accomplishments have been made in the area of D. salina molecular biology, genetic work with this alga warrants additional investigation. In addition to the chloroplast and mitochondrial genomes of D. salina CCAP 19/18, it is anticipated that the recent release of the nuclear genome will greatly encourage further genetic and metabolic engineering of this organism.

In the same way that computers are the coupling of software and hardware, microalgal cultivation systems rely on both the algal organism being grown and the vessel used to amass the cells. While one piece of software can potentially be run on various hardware devices, the two are often developed together and designed accordingly; the same is true with algal culture systems. Whether the growth environment is a raceway pond or a photobioreactor, there exist innumerable prospective algal species that could be cultivated. As the field of microalgal biotechnology moves more toward engineered algae and highperformance PBRs, the unique qualities of the organism will be paired with bioreactor design considerations. Just as the computing power of microchips is always increasing and new versions of operating systems are ever more frequently available, it is expected that algal species that are selected or engineered for high productivity will constantly demand more of their cultivation systems and vice versa.

\section{References}

Akama K., Puchta H., \& Hohn B. 1995. Efficient Agrobacterium-mediated transformation of Arabidopsis thaliana using the bar gene as selectable marker. Plant Cell Rep 14:450545 .

Benemann J.R. \& Oswald W.J. 1996. Algal mass culture systems. In Systems and Economic Analysis of Microalgae Ponds for Conversion of CO2 to Biomass. US Department of Energy, Pittsburgh, PA, pp. 42-65.

Benning C. 2008. A role for lipid trafficking in chloroplast biogenesis. Progess in Lipid Research 47:381-389.

Chen T., Liu H., Lu P., \& Xue L. 2009. Construction of Dunaliella salina heterotrophic expression vectors and identification of heterotrophically transformed algal strains. Chinese Journal of Biotechnology 25:392-398.

Chisti Y. 2007. Biodiesel from microalgae. Biotechnology Advances. 25:294-306.

Chitlaru E. \& Pick U. 1991. Regulation of glycerol synthesis in response to osmotic changes in Dunaliella Plant Physiology 96:50-60. 
Danquah M.K., Gladman B., Moheimani N., \& Forde G.M. 2009. Microalgal growth characteristics and subsequent influence on dewatering efficiency. Chemical Engineering Journal 151:73-78.

European Parliament. 2009. Directive 2009/28/EC, L 140. pp. 16-59

Feng S., Xue L., Liu H. and Lu P. 2009. Improvement of efficiency of genetic transformation for Dunaliella salina by glass beads method. Molecular Biology Reports 36:1433-1439.

Fortman J.L., Chhabra S., Mukhopadhyay A., Chou W., et al. 2008. Biofuel alternatives to ethanol: pumping the microbial well. Trends in Biotechnology 26:375-381.

Geng D., Wang Y., \& Wang P. 2003. Stable expression of hepatitis B surface antigen gene in Dunaliella salina. J Appl Phycol 15:451-456.

Gordon J.M. \& Polle J.E.W. 2007. Ultrahigh bioproductivity from algae. Appl Microbiol Biotechnol 76:969-975.

Gouveia L. and Oliveira A.C. 2009 Microalgae as raw material for biofuels production. J Ind Microbial Biotechnol 36:269-274.

Goyal A. 2007. Osmoregulation in Dunaliella, Part II: Photosynthesis and starch contribute carbon for glycerol synthesis during a salt stress in Dunaliella tertiolecta. Plant Physiology and Biochemistry 45:705-710.

Hallmann A. 2007. Algal Transgenics and Biotechnology. Transgenic Plant Journal 1:81-98.

Hallmann A. \& Rappel A. 1999. Genetic engineering of the multicellular green alga Volvox: a modified and multiplied bacterial antibiotic resistance gene as a dominant selectable marker. The Plant Journal 17:99-109.

Harris E.H. 2001. Chlamydomonas as a Model Organism. Annu Rev Plant Physiol Plant Mol Biol 52:363-406.

Hejazi M.A., Holwerda E. \& Wijffels R.H. 2004a. Milking microalga Dunaliella salina for $\beta$ carotene production in two phase bioreactors. Biotechnol Bioeng 85:475-481.

Hejazi M.A., Kleinegris D. \& Wijffels R.H. 2004b. Mechanisms of extraction of $\beta$ carotene from Dunaliella salina in two-phase bioreactors. Biotechnol Bioeng 88:593-600.

Hoerlein G. 1994. Glufosinate (phosphinothricin), a natural amino acid with unexpected herbicidal properties. Rev Environ Contam Toxicol 138:73-145.

Hoffert M.I., Caldeira K., Jain A.K., Haites E.F., et al. 1998. Energy Implications of future stabilization of atmospheric CO2 content. Nature 395:881-884.

$\mathrm{Hu}$ Q., Guterman H. \& Richmond A. 1996. A flat inclined modular photobioreactor for outdoor mass cultivation of photoautotrophs. Biotechnol Bioeng 51:51-60.

Huntely M.E. \& Redalje D.G. 2007. $\mathrm{CO}_{2}$ mitigation and renewable oil from photosynthetic microbes: a new appraisal. Mitigation and Adaptation Strategies for Global Change 12:573-608.

Jakobiak T., Mages W., Scarf B., Babinger P., et al. 2004. The bacterial paromomycin resistance gene, aphH, as a dominant selectable marker in Volvox carteri. Protist 155:381-393.

Jamers A., Blust R., \& Coen W.D. 2009. Omics in algae: Paving the way for a systems biological understanding of algal phenomena? Aquatic Toxicology 92:114. 
Janssen M., Tramper J., Mur L.R., \& Wijffels R.H. 2003. Enclosed outdoor photobioreactors: light regime, photosynthetic efficiency, scale-up, and future prospects. Biotechnol Bioeng 81:193-210.

Jia Y., Xue L., \& H. Liu J.L. 2009a. Characterization of the glyceraldehyde-3-phosphate dehydrogenase (GAPDH) dene from the halotolerant alga Dunaliella salina and inhibition of its expression by RNAi. Current Microbiology 58:426-431.

Jia Y., Xue L., Li J., \& Liu H. 2009b. Isolation and proteomic analysis of the halotolerant alga Dunaliella salina flagella using shotgun strategy. Journal 2009.

Jiang G.-Z., Lu Y.-M., Niu X.-L., \& Xue L.-X. 2005. The actin gene promoter-driven bar as a dominant selectable marker for nuclear transformation of Dunaliella salina. Acta Cenetica Sinica 32:424-433.

Jiang G.Z., Nu X.L., Lu Y.M., Xie H., et al. 2003. Cloning and characterization of Hsp70a cDNA fragment of Dunaliella salina. Yi Chuan 25: 573-576.

Jin E.S., Polle E.W., \& Melis A. 2001. Involvement of zeaxanthin and of the Cbr protein in the repair of photosystem II from photoinhibition in the green alga Dunaliella salina. Biochim Biophys Acta 1506:244-259.

Lamers P.P., Janssen M., Vos R.C.H.D., Binoand R.J., et al. 2004. Exploring and exploiting carotenoid accumulation in Dunaliella salina for cell-factory applications. Trends Biotechnol 26:631-638.

Leon-Banares R., Gonzalez-Ballester D., Galvan A., \& Fernandez E. 2004. Transgenic microalgae as green cell factories. Trends in Biotechnology 22:45-52.

Li J., Xue L., Yan H., Wang L., et al. 2007. The nitrate reductase gene-switch: a system for regulated expression in transformed cells of Dunaliella salina. Gene 403:132-142.

Liska A.J., Shevchenko A., Pick U., \& Katz A. 2004. Enhanced photosynthesis and redox energy production contribute to salinity tolerance in Dunaliella as revealed by homology-based proteomics. Plant Physiology 136:2806-2817.

Liu H.T., Zang W.D., Lu Z.M., Wang N., et al. 2005. Cloning and analysis of psaB cDNA of Dunaliella salina. Chinese Journal of Biotechnology 21:643-645.

Long S.P., Humphries S., \& Falkowski P.G. 1994. Photoinhibition of photosynthesis in nature. Annu Rev Plant Physiol Plant Mol Biol 45:633-662.

Lu P., Yan H., Li J., Liu H., et al. 2009. An optimal electroporation system for Dunaliella salina. Chinese Journal of Biotechnology 25:520-525.

Lumbreras V., Stevens D.R., \& Purton S. 1998. Efficient foreign gene expression in Chlamydomonas reinhardtii mediated by an endogenous intron. Plant J 14:441447.

Miller S.M. 2002. Taming the fierce roller: an "enhanced" understanding of cellular differentiation in Volvox. Bioessays 24:3-7.

Miron A.S., Gomez A.C., Camacho F.G., Grima E.M., et al. 1999. Comparative evaluation of compact photobioreactors for large-scale monoculture of microalgae. Journal of Biotechnology 70:249-270.

Muller-Feuga A. 2004. Microalgae for Aquaculture: The current global situation and future trends, Blackwell Science. 
Mussgnug J.H., Thomas-Hall S., Rupprech J., Foo A., et al. 2007. Engineering photosynthetic light capture: impacts on improved solar energy to biomass conversion. Plant Biotechnol J 5:802-814.

Nitschke W.R. and Wilson C.M. 1965. Rudolph Diesel, pioneer of the age of power. The University of Oklahoma Press, Norman, OK.

Olmos J., Paniagua J., \& Contreras R. 2000. Molecular identification of Dunaliella sp. utilizing the 18S rDNA gene. Letters in Applied Microbiology 30:80-84.

Polle J.E.W. \& Qin S. 2009. Development of genetics and molecular tool kits for species of the unicellular green alga Dunaliella (Chlorophyta) Science Publishers (USA), Enfield, $\mathrm{NH}$.

Polle J.E.W., Struwe L., \& Jin E. 2008. Identification and characterization of a new strain of the unicellular green alga Dunaliella salina (Teod.) from Korea. J Microbiol Biotechnol 18:821-827.

Qiu B., Liu J., Liu Z., \& Liu S. 2002. Distribution and ecology of the edible cyanobacterium Ge-Xian-Mi (Nostoc) in rice fields of Hefeng County in China. Journal of Applied Phycology 14:423-429.

Raja R., Hemaiswarya S., Kumar N.A., Sridhar S., et al. 2008. A perspective on the biotechnological potential of microalgae. Critical Review in Microbiology 34:77-88.

Shaish A., Ben-Amotz A., \& Avron M. 1992. Biosynthesis of beta-carotene in Dunaliella. Methods Enzymol 213:439-444.

Sheehan J., Dunahay T., Benemann J., \& Roessler P. 1998. A Look Back at the U.S. Department of Energy's Aquatic Species Program: Biodiesel from Microalgae. TP580-24190. National Renewable Energy Lab, Golden, Colorado.

Schiedlmeier B., Schmitt R., Muller W., Kirk M.M., Gruber H., Mages W., \& Kirk D.L. 1994. Nuclear transformation of Volvox carteri. Proc Natl Acad Sci USA, 91:50805084.

Shelef G., Sukenik A., \& Green M. 1984. Microalgae harvesting and processing: a literature review. Solar Energy Research Institute, pp. 1-65.

Schenk P.M., Thomas-Hall S.R., Stephens E., Marx U.C., Mussgnug J.H., Posten C., Kruse O., Hankamer B. 2008. Seconds generation biofuels: high-efficiency microalgae for biodiesel production. Bioenergy Research. 1:20-43.

Sillers R., Show A., Tracy B., \& Papoutsakis E.T. 2008. Metabolic engineering of the nonsporulating, non-solventogenic Clostridium acetobutylicum strain M5 to produce butanol without acetone demonstrate the robustness of the acid-formation pathways and the importance of the electron balance. Metabolic Engineering 10:321.

Sizova I., Fuhrmann M., \& Hegemann P. 2001. A Streptomyces rimosus aphVIII gene coding for a new type phosphotransferase provides stable antibiotic resistance to Chlamydomonas reinhardtii. Gene 277:221-229.

Smith D.R., Lee R.W., Cushman J.C., Magnuson J.K., Tran D., \& Polle J.E.W. 2010. The Dunaliella salina organelle genomes: large sequences, inflated with intronic and intergenic DNA. BMC Plant Biology, 10:83.

Smolinska J. 2008. EU Economic Report. ACEA - European Automobile Manufacturers' Association. 
Spolaore P., Joannis-Cassan C., Duran E., \& Isambert A. 2006. Commercial applications of microalgae. Journal of Bioscience and Bioengineering 101:87-96.

Sun G., Zhang X., Sui Z., \& Mao Y. 2008. Inhibition of pds gene expression via the RNA interference approach in Dunaliella salina (Chlorophyta). Mar Biotechnol 10:219226.

Sun Y., Yang Z., Gao X., Li Q., et al. 2005. Expression of foreign genes in Dunaliella by electroporation. Mol Biotechnol 30:185-192.

Tan C., Quin S., Zhang Q., Jiang P., et al. 2005. Establishment of a micro-particle bombardment transformation system for Dunaliella salina. J Microbiol 43:361365.

Thompson C.J., Movva N.R., Tizard R., Crameri R., et al. 1987. Characterization of the herbicide-resistance gene bar from Streptomyces hygroscopicus. EMBO J 6:25192523.

Thompson G.A. 2005. Mechanisms of osmoregulation in the green alga Dunaliella salina. Journal of Experimental Zoology 268:127-132.

Tredici M.R. and Zittelli G.C. 1998. Efficiency of sunlight utilization: tubular versus flat photobioreactors. Biotechnol Bioeng 57:187-197.

Ugwu C.U., Aoyagi H., \& Uchiyama H. 2008. Photobioreactors for mass cultivation of algae. Bioresource Technology 99:4021-4028.

U.S. Energy Information Administration. Annual Energy Outlook 2009 with Projections to 2030. DOE/EIA-0383(2009).

Vemuri G.N. \& Aristidou A.A. 2005. Metabolic engineering in -omics era: elucidating and modulating regulatory networks. Microbiology and Molecular Biology Reviews 69:197216.

Walker T.L., Becker D.K., \& Collet C. 2004. Characterisation of the Dunaliella tertiolecta RbcS genes and their promoter activity in Chlamydomonas reinhardtii. Plant Cell Rep 23:727-735.

Walker T.L., Collet C., \& Purton S. 2005. Algal transgenics in the genomic era. Journal of Phycology 41:1077-1093.

Wallace R., Ringer M., Pienkos P. 2008. National Renewable Energy Laoratory (NREL) Report to Congress: Algal Biofuels.

Wang T., Xue L., Hou W., Yang B., et al. 2007. Increased expression of transgene in stably transformed cells of Dunaliella salina by matrix attachment regions. Applied Microbiology and Biotechnology 76:651-657.

Wang T., Xue L., Xiang J., Li J., et al. 2009. Cloning and characterization of the 14-3-3- protein gene from the halotolerant alga Dunaliella salina. Molecular Biology Reports 36:207214.

Weldy C.S. \& Huesemann M. 2007. Lipid production by Dunaliella salina in batch culture: effects of nitrogen limitation and light intensity. U.S. Department of Energy Journal of Undergraduate Research 7:115-122.

Weyer K., Bush D., Darzins A., \& Wilson D. October 24, 2008. Theoretical Maxium Algal Oil Production. Algae Biomass Summit Solix.

Wu Q. \& Miao X. 2006. Biodiesel production from heterotrophic microalgal oil. Bioresource Technology 97:841-846. 
Xie H., Xu P., Jia Y., Li J., et al. 2007. Cloning and heterologous expression of nitrate reductase genes from Dunaliella salina. J Appl Phycol 19:497-504.

Ye Z.-W., Jiang J.-G., \& Wu G.-H. 2008. Biosynthesis and regulation of carotenoids in Dunaliella: Progresses and prospects. Biotechnol Advances 26:352-360. 


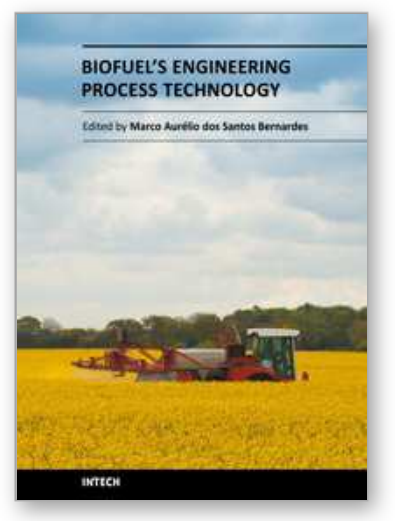

\author{
Biofuel's Engineering Process Technology \\ Edited by Dr. Marco Aurelio Dos Santos Bernardes
}

ISBN 978-953-307-480-1

Hard cover, 742 pages

Publisher InTech

Published online 01, August, 2011

Published in print edition August, 2011

This book aspires to be a comprehensive summary of current biofuels issues and thereby contribute to the understanding of this important topic. Readers will find themes including biofuels development efforts, their implications for the food industry, current and future biofuels crops, the successful Brazilian ethanol program, insights of the first, second, third and fourth biofuel generations, advanced biofuel production techniques, related waste treatment, emissions and environmental impacts, water consumption, produced allergens and toxins. Additionally, the biofuel policy discussion is expected to be continuing in the foreseeable future and the reading of the biofuels features dealt with in this book, are recommended for anyone interested in understanding this diverse and developing theme.

\title{
How to reference
}

In order to correctly reference this scholarly work, feel free to copy and paste the following:

Julian N. Rosenberg, Michael J. Betenbaugh and George A. Oyler (2011). Paving the Road to Algal Biofuels with the Development of a Genetic Infrastructure, Biofuel's Engineering Process Technology, Dr. Marco Aurelio Dos Santos Bernardes (Ed.), ISBN: 978-953-307-480-1, InTech, Available from:

http://www.intechopen.com/books/biofuel-s-engineering-process-technology/paving-the-road-to-algal-biofuelswith-the-development-of-a-genetic-infrastructure

\section{INTECH}

open science | open minds

\author{
InTech Europe \\ University Campus STeP Ri \\ Slavka Krautzeka 83/A \\ 51000 Rijeka, Croatia \\ Phone: +385 (51) 770447 \\ Fax: +385 (51) 686166 \\ www.intechopen.com
}

\author{
InTech China \\ Unit 405, Office Block, Hotel Equatorial Shanghai \\ No.65, Yan An Road (West), Shanghai, 200040, China \\ 中国上海市延安西路65号上海国际贵都大饭店办公楼405单元 \\ Phone: +86-21-62489820 \\ Fax: +86-21-62489821
}


(C) 2011 The Author(s). Licensee IntechOpen. This chapter is distributed under the terms of the Creative Commons Attribution-NonCommercialShareAlike-3.0 License, which permits use, distribution and reproduction for non-commercial purposes, provided the original is properly cited and derivative works building on this content are distributed under the same license. 